\title{
Retinol derivative as bioinitiator in the synthesis of hydroxyl-functionalized polymethacrylates for micellar delivery systems
}

\author{
J. Odrobińska, D. Neugebauer \\ Department of Physical Chemistry and Technology of Polymers, Faculty of Chemistry, Silesian University of Technology, \\ Strzody 9, 44-100 Gliwice, Poland
}

Received 3 February 2019; accepted in revised form 30 April 2019

\begin{abstract}
Amphiphilic copolymers containing 2-hydroxyethyl methacrylate (HEMA) and methyl methacrylate (MMA) units were synthesized by controlled atom transfer radical polymerization (ATRP) applying bromoester modified retinol (RETBr) as a novel initiator. Analogous series of copolymers with adjustable hydrophilic-hydrophobic balance was obtained with the use of a standard initiator, i.e. ethyl $\alpha$-bromoisobutyrate (EBriB). The self-assembling particles, prepared by the solvent evaporation, were loaded with vitamin $\mathrm{C}$ (VitC) or ferulic acid (FA). The hydrophilic/hydrophobic ratio in the copolymer was indicated as a crucial factor to regulate efficiencies of encapsulation processes in the range of 53-98\%. In vitro release of bioactive substance was carried out in phosphate buffer solution (PBS) at pH 7.4 with the maximum amount of VitC after $1 \mathrm{~h}(27-62 \%)$ or FA within $2 \mathrm{~h}(71-97 \%)$. The polymeric systems with satisfactory encapsulation characteristics and release profiles are attractive micellar carriers of antioxidants, which, due to their activities could be also delivered using the popular approaches in cosmetology like masks, under-eye patches, or wraps.
\end{abstract}

Keywords: tailor-made polymers, nanomaterials, bioinitiator, antioxidants, delivery systems

\section{Introduction}

Retinol (RET, also known as vitamin A), which is the popular component of cosmetic products, belongs to the group of fat-soluble hydrophobic vitamins indicating good penetration into the epidermis and recovery effect, especially with regard to skin disorders like wrinkles, acne and hyperpigmentation [1]. RET improves elasticity of the skin because it stimulates collagen and glycosaminoglycans synthesis. The anti-aging properties are the consequence of the prevented oxidation stress and the delayed/inhibited matrix degradation by blocking the enzymes which decompose collagen [2]. In addition, RET eliminates sun and hormonal skin discolorations by reducing the size of melanocytes and the amount of melamine. RET as terpene alcohol has already been applied as the initiator of the ring-opening polymerization (ROP) of ethylene oxide [3] or lactide [4] resulting in welldefined biohybrid polymers with potential applications as liquid crystalline materials, amphiphilies, or conjugate systems targeted to stellate liver cells. However, according to the literature the delivery of RET is supported by encapsulation strategy, mostly into chitozan [5-7], and polyester (polyadipates, polycaprolactone) [8] nanoparticles. Moreover, spherical inorganic particles containing RET have been fabricated using silica in combination with surfactants and hydroxypropyl cellulose [9], tetraethyl orthosilicate sol-gel systems [10], or polyphosphates with calcium ions [11]. The alternative systems entrapping RET are represented by solid lipid nanoparticles based on glyceryl behenate $[12,13]$. 
Similarly to RET, vitamin C (VitC also known as ascorbic acid) is often used in cosmetics because of its excellent rejuvenating effects. It also eliminates discoloration caused by tanning and strengthens blood vessels. VitC as a cofactor of proline and lysine hydroxylase, the key enzymes that cross-link and stabilize collagen fibers [14], stimulates the synthesis of collagen as well as demonstrates antioxidant properties [2, 15]. Moreover, vitamin A - vitamin $C$ complex causes an increase in skin elasticity and reduces the signs of skin aging [2].

The low toxic ferulic acid (FA, 4-hydroxy-3-methoxycinnamic acid), which can be absorbed to be easily metabolized in the human body, is another ingredient in cosmetics [16]. The main physiological functions are related to antioxidant, antimicrobial, anti-thrombosis, anti-collagenase, and anti-cancer activities [17]. FA protects against ultraviolet (UV) radiation and reduces skin hyperpigmentation [18]. The introduction of FA into chitosan-polycaprolactone coreshell nanofibers has supported their efficacy in proangiogenic and anti-inflammatory activities [19]. The complex of FA/cyclodextrin representing high degree of photostability and high association constant has found application in sunscreen delivery systems [20].

Herein, we report the synthesis of two series of amphiphilic copolymers based on 2-hydroxyethyl methacrylate (HEMA). It is well known that linear, graft, and cross-linked polymers [21,22] or peptide/ polymer conjugates [23] based on HEMA are attractive biomaterials for contact lenses, gene and drug delivery [24]. The biocompatible HEMA/MMA copolymers [25-28] have been extended by polymethacrylate segment with PEG grafts [29], grafted from the surface of $\mathrm{TiO}_{2}$ nanoparticles [30], or modified to $\mathrm{Fe}_{3} \mathrm{O}_{4}$ containing nanocomposite $\mathrm{pH}$-responsive systems for anticancer drug delivery [31]. In our work, a new bioinitiator, that is retinol, modified with bromoester group was synthesized and applied in the atom transfer radical polymerization (ATRP) of methacrylate comonomers to achieve retinol endcapped P(HEMA-co-MMA)s with different content of hydroxy-functionalized units (Figure 1). For comparison, analogous copolymers were prepared by classical ATRP $\alpha$-bromoester initiator. These polymers were subjected to micellization, and encapsulation of the antioxidants applied in cosmetology (VitC or FA). Because of that the release process was investigated in neutral environment to imitate the skin conditions. An additional advantage of the carriers based on the obtained amphiphilic polymers corresponds to retinol end-capped group, which is safe for humans.

\section{Experimental section}

\subsection{Materials}

Methyl methacrylate (MMA, Alfa Aesar, 99\%), 2-hydroxyethyl methacrylate (HEMA, Aldrich, 97\%) and anisole (Alfa Aesar, 99\%) were dried over molecular sieves and stored in a freezer under nitrogen. Cooper(I) bromide (CuBr, Fluka, 98\%) were purified by stirring in glacial acetic acid followed by filtration and washing with ethanol and diethyl ether. After that the solids were dried under vacuum. 4,4-Dinonyl-2,2-dipyridyl (dNdpy, Aldrich, 97\%),

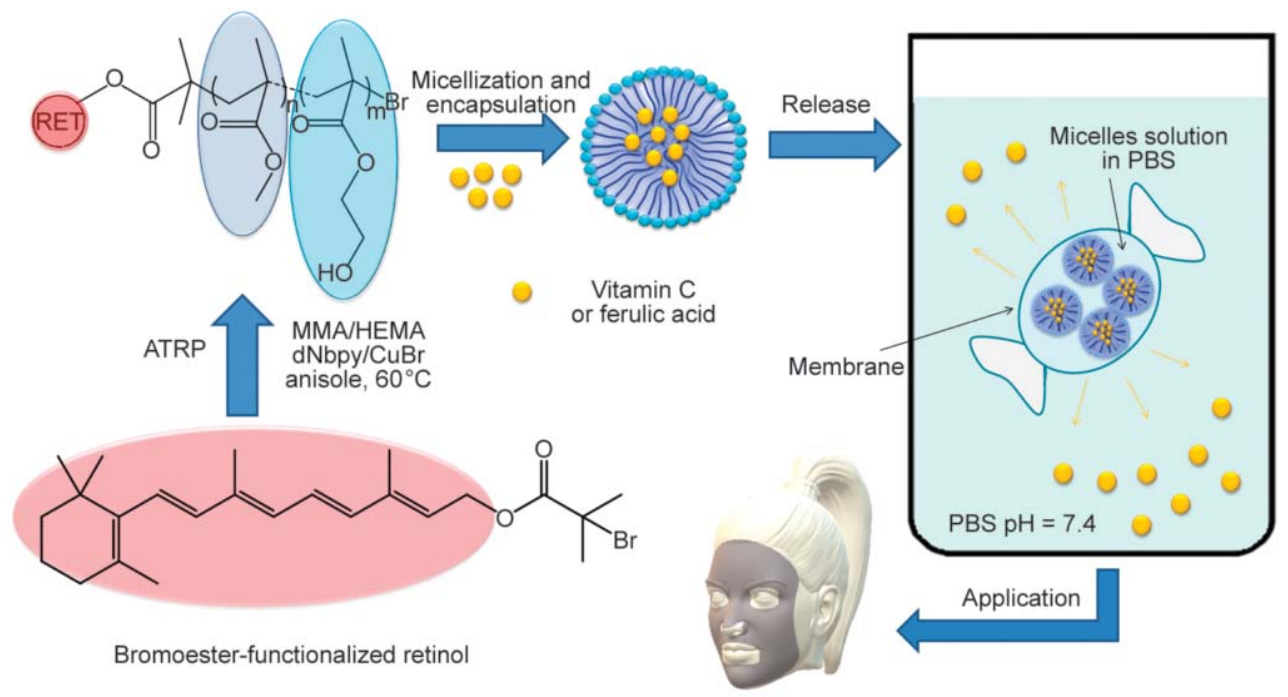

Figure 1. Synthesis of amphiphilic copolymers of MMA/HEMA with RETBr bioinitiator and preparation of nanoparticles for the potential skin care applications. 
triethylamine (TEA, Aldrich, 99\%), pyridine (Aldrich, 99\%), 2-bromoisobutyryl bromide (BriBuBr, Aldrich, 98\%), ethyl $\alpha$-bromoisobutyrate (EBriB, Aldrich, 98\%), all-trans-retinol (RET, Acros, 95\%), L(+)-ascorbic acid (VitC, Chempure, 99\%, Poland), ferulic acid (FA, Acros, 99\%), 0.1 M sodium phosphate buffer solution (PBS; $\mathrm{pH}=7.4$, Aldrich) were used as received. All other chemicals were applied without purification.

\subsection{Methods}

\subsubsection{Synthesis of retinol-2-bromoisobutyrate (RETBr)}

A $0.2 \mathrm{~g}(0.698 \mathrm{mmol})$ of RET was solved into a $100 \mathrm{ml}$ round-bottom flask with $10 \mathrm{ml}$ of chloroform yielding yellow solution. Then TEA $(0.101 \mathrm{ml}$, $0.728 \mathrm{mmol}$ ) was added dropwise to the solution.

The reactor was cooled to $0{ }^{\circ} \mathrm{C}$ in an ice/water bath and $\operatorname{BriBuBr}(0.09 \mathrm{ml}, 0.728 \mathrm{mmol})$ was dropped. The reaction mixture was stirred for $48 \mathrm{~h}$ at room temperature. After that it was transferred into a separator with chloroform and extracted consecutively with $\mathrm{H}_{2} \mathrm{O}(3 \times 100 \mathrm{ml})$ and saturated $\mathrm{NaCl}$ solution $(3 \times 100 \mathrm{ml})$. The organic phase was dried over anhydrous $\mathrm{MgSO}_{4}$, filtered off and removed by rotary evaporation. The product, oily brown liquid, was dried under vacuum to constant mass. Yield: $93 \%$. ${ }^{1} \mathrm{H}$ NMR (600 MHz, DMSO, ppm): 6.50-6.60 (2H, $\left.2^{*}=\mathrm{CH}-\right), 6.25-3.35(1 \mathrm{H},=\mathrm{CH}-), 6.10-6.20(2 \mathrm{H}$, $\left.2^{*}=\mathrm{CH}-\right), 5.60-5.65(1 \mathrm{H},=\mathrm{CH}-), 4.09-4.12(2 \mathrm{H}$, $\left.-\mathrm{O}-\mathrm{CH}_{2}-\right), 1.98-2.02\left(2 \mathrm{H},-\mathrm{CH}_{2}-\right.$ ring $), 2.00(6 \mathrm{H}$, $\left.-\left(\mathrm{CH}_{3}\right)_{2} \mathrm{Br}\right), 1.90-1.92\left(3 \mathrm{H},-\mathrm{CH}_{3}\right.$ ring), $1.75-1.80$ ( $3 \mathrm{H},-\mathrm{CH}_{3}$ aliphat.), $1.65-1.70\left(3 \mathrm{H},-\mathrm{CH}_{3}\right.$ aliphat.), $1.52-1.60\left(2 \mathrm{H},-\mathrm{CH}_{2}-\right.$ ring $), 1.40-1.48\left(2 \mathrm{H},-\mathrm{CH}_{2}-\right.$ ring), $0.95-1.02\left(6 \mathrm{H}, 2^{*}-\mathrm{CH}_{3}\right.$ ring). ESI-MS $(\mathrm{m} / \mathrm{z})$ : calculated for $\mathrm{C}_{24} \mathrm{H}_{35} \mathrm{O}_{2} \mathrm{Br} 434.9$; found for $[\mathrm{M}+\mathrm{H}]^{+}$ 435.1, $[\mathrm{M}+\mathrm{Na}]^{+}$457.2.

\subsubsection{Synthesis of $P(M M A-c o-H E M A)$ with EBriB as initiator (example for IV)}

dNpby (108.75 mg, $0.266 \mathrm{mmol}$ ), MMA (4.27 ml, $39.92 \mathrm{mmol})$, HEMA $(1.62 \mathrm{ml}, 13.31 \mathrm{mmol})$ and anisole $(0.6 \mathrm{ml}, 10 \mathrm{vol} \%$ of monomer $)$ were placed in a Schlenk flask and then degassed by two freezepump-thaw cycles. Then EBriB (19.74 $\mu$, $0.133 \mathrm{mmol}$ ) was added and degassed again. After that $\mathrm{CuBr}(19.09 \mathrm{mg}, 0.133 \mathrm{mmol})$ was added. The reaction flask was immersed in an oil bath at $60^{\circ} \mathrm{C}$. The polymerization was stopped by exposure to air. Then the mixture was dissolved in acetone and passed through neutral alumina column to remove copper catalyst. The solution was concentrated by rotary evaporation. The polymer was precipitated by dropwise addition of a concentrated solution into diethyl ether. The product was isolated by decantation and dried under vacuum to constant mass.

\subsubsection{Synthesis of $P(M M A-c o-H E M A)$ with RETBr as initiator (example for VIII)}

RETBr (35.70 mg, $0.082 \mathrm{mmol})$, dNdpy (67.18 mg, $0.164 \mathrm{mmol})$, MMA (2.64 mL, $24.66 \mathrm{mmol})$, HEMA $(1.00 \mathrm{ml}, 8.22 \mathrm{mmol})$, anisole $(0.36 \mathrm{ml}, 10 \mathrm{vol} \%$ of monomer) were placed in a Schlenk flask and then degassed by three freeze-pump-thaw cycles. After that $\mathrm{CuBr}$ (11.79 mg, $0.082 \mathrm{mmol})$ was added. The reaction flask was immersed in an oil bath at $60^{\circ} \mathrm{C}$. The polymerization was stopped by exposure to air. Due to incomplete solubility of RET-based polymers in acetone the mixture was diluted in methanol and the copper catalyst was efficiently removed by cationite (Dowex). The solution was concentrated by rotary evaporation. The polymer was precipitated by dropwise addition of a concentrated solution into diethyl ether. The product was isolated by decantation and dried under vacuum to constant mass.

\subsubsection{Micellization}

Nanoparticles were prepared via solvent evaporation method. The amphiphilic copolymer (30 mg) was dissolved in methanol $(15 \mathrm{ml})$. Then deionized water (200 vol\% of methanol) was added dropwise under gentle stirring. The reaction was continued overnight to let micelles form. After that, the vial with sample was opened to evaporate organic solvent and then placed in an ultrasonic bath to dissolve the precipitation. The sample was centrifuged, and next the aqueous fraction was collected and lyophilized.

\subsubsection{Encapsulation of active compound into polymeric nanoparticles}

The substance-loaded nanoparticles were prepared according to the same methods as the substance-free ones. Amphiphilic copolymer and FA or VitC were dissolved in $\mathrm{MeOH}$ with the weight ratio of polymer:drug $=1: 1$ and deionized water was added dropwise (200 vol\% of the solvent). Further procedures were similar to those for the 'empty' micelles. A solution of loaded particles in $\mathrm{MeOH}(0.008 \mathrm{mg} / \mathrm{ml})$ was prepared to determine the amount of entrapped substances by UV-Vis spectroscopy measuring 
absorbance at $\lambda=310 \mathrm{~nm}$ for FA and $\lambda=267 \mathrm{~nm}$ for VitC. Drug loading content $(D L C)$ was calculated using Equation (1):

$D L C=\frac{\text { Weight of drug loaded into micelle }}{\text { Weight of total polymer and loaded drug }} \cdot 100 \%$

\subsubsection{Critical micelle concentration $(C M C)$ measurements}

The critical point of polymer aggregation was measured by fluorescence spectrophotometry using pyrene as fluorescence probe. Excitation spectra of pyrene $(\lambda=390 \mathrm{~nm})$ were recorded at constant concentration of pyrene $\left(3.0 \cdot 10^{-4} \mathrm{~mol} / \mathrm{l}\right)$ and polymer concentrations in the range of $5 \cdot 10^{-4}-1.0 \mathrm{mg} / \mathrm{ml}$. The intensity ratio $\left(I_{336} / I_{332}\right)$ from pyrene excitation spectrum vs. $\log C$ (where $C$ is concentration in $\mathrm{mg} / \mathrm{ml}$ ) was plotted, where the cross-over point was estimated as the $C M C$ value.

\subsubsection{Bioactive substance release studies}

FA-loaded micelles or VitC-loaded micelles were dissolved in PBS ( $\mathrm{pH}=7.4 ; 1.0 \mathrm{mg} / \mathrm{ml})$. The solution was introduced into a dialysis cellulose membrane bag (MWCO $3.5 \mathrm{kDa}$ ), which was placed into glass vial with $43 \mathrm{ml}$ of PBS and stirred at $37^{\circ} \mathrm{C}$ in a water bath. Dialysis was carried out for one week. $1.0 \mathrm{ml}$ of the buffer solution sample was taken from the release medium, at appropriate time intervals, to determine the concentration of released drug by UVVis spectroscopy.

\subsection{Characterization}

${ }^{1} \mathrm{H}$ NMR spectra were recorded with UNITY/INOVA (Varian) spectrometer operating at $300 \mathrm{MHz}$ using DMSO as a solvent and tetramethylosilane (TMS) as an internal standard. The monomer conversion was determined by gas chromatography (GC, Agilent Technologies 6850 Network GC System). The measurements were carried out in acetone as the solvent. The signals at different retention times were corresponded to MMA (2.3 min), HEMA ( $8.5 \mathrm{~min}$ ) and anisole (4.9 min). Mass spectrometry (MS, Xevo G2 QTof, Waters Corporation) was used to confirm the molecular masses and regularity of the structure of the functionalized retinol. Molecular weights and dispersity indices were determined by gel permeation chromatography (GPC) equipped with an 1100
Agilent isocratic pump, autosampler, degasser, thermostatic box for columns and differential refractometer MDS RI Detector. The measurements were carried out in THF as the solvent at $30^{\circ} \mathrm{C}$ with flow rate of $0.8 \mathrm{ml} / \mathrm{min}$. The GPC calculations of molecular weights were based on calibration using linear PS standards (580-300000 g/mol). Differential scanning calorimetry (DSC) was used to determine the glass transition temperatures of copolymers. Measurements were carried out on a Mettler Toledo DSC822e. Fourier transform infrared spectroscopy (FT-IR) analysis was conducted with Perkin-Elmer Spectrum Two 1000 FT-IR Infrared Spectrometer using attenuated total reflection (ATR). The particle sizes were measured at $25^{\circ} \mathrm{C}$ using dynamic light scattering (DLS, Zetasizer Nano-S90, Malvern Technologies). The measurements were carried out in PBS ( $\mathrm{pH}=7.4)$. Before measurement some samples $(1.0$ or $0.5 \mathrm{mg} / \mathrm{ml})$ were filtered through syringe filters (pore size $0.45 \mu \mathrm{m}$ ). The critical point of polymer aggregation was measured by fluorescence spectrophotometry (FL, Hitachi F-2500). Obtained micelles were tested for the release of active substances. The samples taken during the release process were analyzed by ultraviolet - visible spectroscopy (UV-Vis, Thermo Fisher Scientific Evolution 300) to determine the DLE and the amount of released substance over time. The measurements are carried out in poly(methyl methacrylate) cuvettes.

\section{Results and discussion \\ 3.1. Synthesis of amphiphilic copolymers of MMA/HEMA}

Two series of polymers were synthesized by ATRP using as the initiator bromoester-functionalized retinol (RETBr) or standard ATRP initiator EBriB with $\mathrm{CuBr} / \mathrm{dNbpy}$ catalyst system in anisole at $60^{\circ} \mathrm{C}$. The comonomer pair (HEMA/MMA) with different initial proportions $(25 / 75,50 / 50,75 / 25)$ was applied to control the hydrophilicity of polymers with statistical distribution of both types of units. For comparison homopolymers (PHEMA) were also prepared. The use of RETBr caused a formation of polymers with lower DP's at significantly extended reaction time than in case of the common EBriB. In both series the lowest monomer conversions and the longest reaction time were provided by systems with the highest content of the hydrophobic fraction (IV, VIII). The detailed data of characteristics for the obtained polymers are summarized in Table 1 and Table 2. 
Table 1. Data for synthesis of HEMA/MMA copolymers by ATRP with EBriB initiator.

\begin{tabular}{|c|c|c|c|c|c|c|c|c|c|c|}
\hline \multirow{3}{*}{ No. } & \multirow{3}{*}{$\begin{array}{c}M_{1} / M_{2} \\
\text { HEMA/MMA }\end{array}$} & \multirow{3}{*}{$\begin{array}{l}\text { Time } \\
{[\mathrm{min}]}\end{array}$} & ${ }^{1}$ H NMR & \multicolumn{5}{|c|}{ GC } & \multicolumn{2}{|c|}{ GPC } \\
\hline & & & $\begin{array}{c}\text { Conversion } \\
{[\%]}\end{array}$ & \multicolumn{2}{|c|}{$\begin{array}{c}\text { Conversion } \\
{[\%]}\end{array}$} & \multicolumn{2}{|c|}{$D P_{\mathrm{n}}$} & \multirow{2}{*}{$\begin{array}{c}M_{\mathrm{n}} \\
{[\mathrm{g} / \mathrm{mol}]}\end{array}$} & \multirow{2}{*}{$M_{\mathrm{w}} / M_{\mathrm{n}}$} & \multirow{2}{*}{$\begin{array}{c}M_{\mathrm{n}} \\
{[\mathrm{g} / \mathrm{mol}]}\end{array}$} \\
\hline & & & HEMA & HEMA & ММА & HEMA & MMA & & & \\
\hline I & $100 / 0$ & 10 & 42 & 42 & - & 168 & - & 22000 & \multicolumn{2}{|c|}{ nd } \\
\hline II & $75 / 25$ & 15 & 53 & 47 & 44 & 141 & 44 & 23000 & 1.29 & 3400 \\
\hline III & $50 / 50$ & 20 & 47 & 45 & 45 & 90 & 90 & 20900 & 1.53 & 21000 \\
\hline IV & $25 / 75$ & 240 & 42 & 32 & 38 & 32 & 114 & 15900 & 1.35 & 19000 \\
\hline
\end{tabular}

$\left[M_{1}+M_{2}\right]_{0} /[\mathrm{EBriB}]_{0} /[\mathrm{CuBr}] 0 /[\mathrm{dNdpy}]_{0}=400 / 1 / 1 / 2$; anisole $10 \mathrm{vol} \%$ of mon., $60^{\circ} \mathrm{C}$; nd: not determined due to polymer insolubility in THF

Table 2. Data for synthesis of HEMA/MMA copolymers by ATRP with RETBr bioinitiator.

\begin{tabular}{|c|c|c|c|c|c|c|c|c|c|c|}
\hline \multirow{3}{*}{ No. } & \multirow{3}{*}{$\begin{array}{c}M_{1} / M_{2} \\
\text { HEMA/MMA }\end{array}$} & \multirow{3}{*}{$\begin{array}{l}\text { Time } \\
\text { [min] }\end{array}$} & ${ }^{1} \mathrm{H}$ NMR & \multicolumn{5}{|c|}{ GC } & \multicolumn{2}{|c|}{ GPC } \\
\hline & & & $\begin{array}{c}\text { Conversion } \\
{[\%]}\end{array}$ & \multicolumn{2}{|c|}{$\begin{array}{c}\text { Conversion } \\
{[\%]}\end{array}$} & \multicolumn{2}{|c|}{$D P_{\mathrm{n}}$} & \multirow{2}{*}{$\begin{array}{c}M_{\mathrm{n}} \\
{[\mathrm{g} / \mathrm{mol}]}\end{array}$} & \multirow{2}{*}{$M_{\mathrm{w}} / M_{\mathrm{n}}$} & \multirow{2}{*}{$\begin{array}{c}M_{\mathrm{n}} \\
{[\mathrm{g} / \mathrm{mol}]}\end{array}$} \\
\hline & & & HEMA & HEMA & MMA & HEMA & MMA & & & \\
\hline V & $100 / 0$ & 45 & 22 & 25 & - & 100 & - & 13600 & \multicolumn{2}{|c|}{ nd } \\
\hline VI & $75 / 25$ & 20 & 33 & 26 & 39 & 78 & 39 & 14500 & 1.46 & 4900 \\
\hline VII & $50 / 50$ & 60 & 34 & 35 & 41 & 70 & 82 & 17700 & 1.30 & 5700 \\
\hline VIII & $25 / 75$ & 220 & 22 & 19 & 21 & 19 & 63 & 9200 & 1.44 & 14500 \\
\hline
\end{tabular}

$\left[M_{1}+M_{2}\right]_{0} /[\mathrm{EBriB}]_{0} /[\mathrm{CuBr}] 0 /[\mathrm{dNdpy}]_{0}=400 / 1 / 1 / 2$; anisole 10 vol $\%$ of mon., $60^{\circ} \mathrm{C}$;

nd: not determined due to polymer insolubility in THF

The relatively low dispersity indices (1.29-1.53) confirmed narrow molecular weight distributions as the effects of the well-controlled polymerization processes. In most of the obtained copolymers the GPC traces were monomodal and symmetrical (Figure 2). The structures of the polymers were confirmed by ${ }^{1} \mathrm{H}$ NMR analysis (Figure 3 ). The conversion of HEMA was determined from ${ }^{1} \mathrm{H}$ NMR spectrum using protons in methylene groups $\left(-\mathrm{COO}-\mathrm{CH}_{2}-\right)$ by

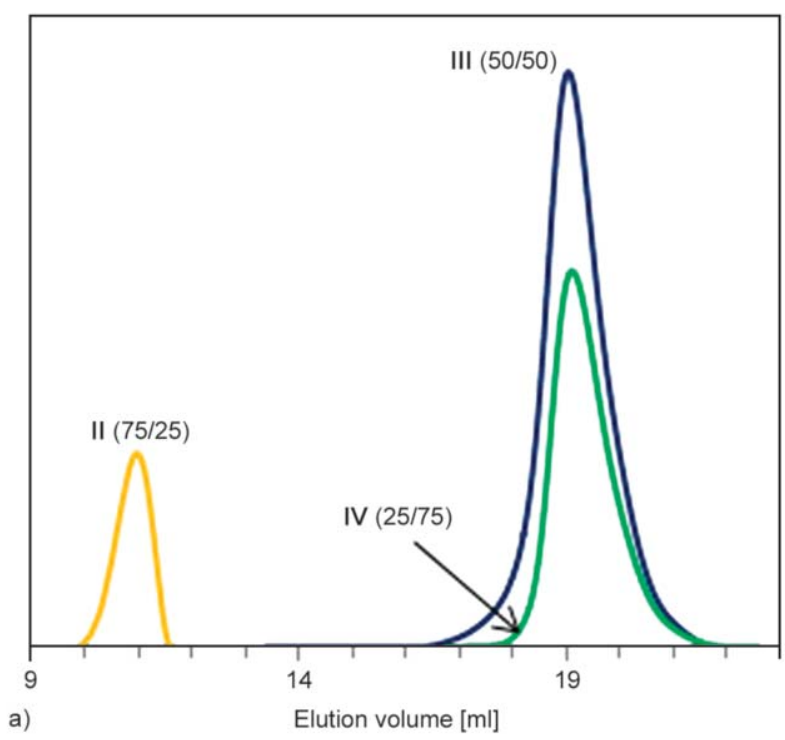

integration of signals corresponding to the monomer (4.1 ppm, $\left.\mathrm{C}_{\mathrm{m}}\right)$ and polymer $\left(3.8-4.0 \mathrm{ppm}, \mathrm{C}_{\mathrm{p}}\right)$. Because the signals crucial for calculation of MMA conversion $\left(-\mathrm{O}-\mathrm{CH}_{3}, \mathrm{D}\right)$ were overlapped with HEMA signals $\left(-\mathrm{CH}_{2}-\mathrm{OH}, \mathrm{B}\right)$, it was completed by $\mathrm{GC}$ analysis, which let to evaluate both monomer conversions and degree of polymerization $\left(D P_{\mathrm{n}}\right)$. The values of HEMA conversions obtained by the NMR and GC analyses indicated agreement with

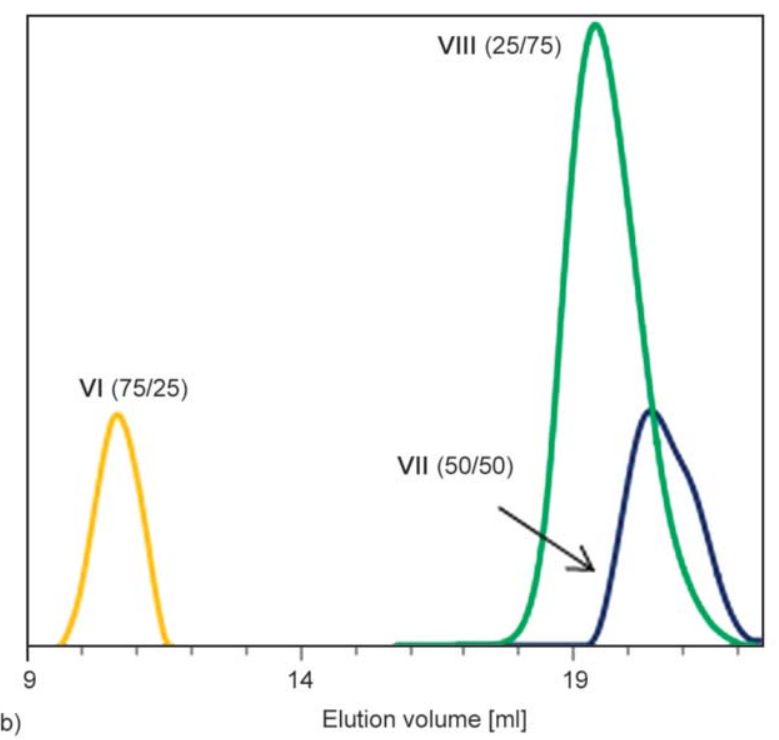

Figure 2. GPC traces for copolymers EBriB/HEMA/MMA (a) and RETBr/HEMA/MMA (b). 


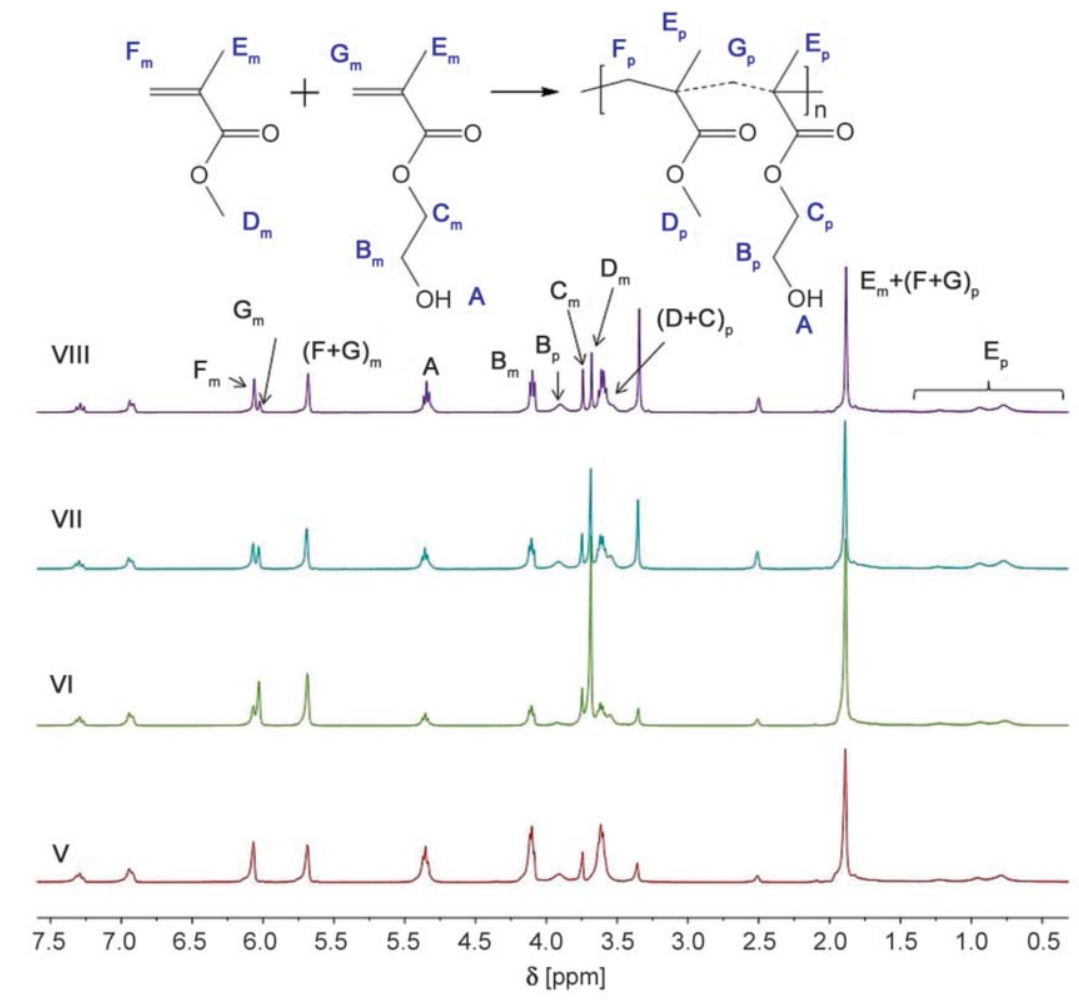

Figure 3. ${ }^{1} \mathrm{H}$ NMR spectra of the samples taken from the reaction mixture for RETBr initiated copolymerization of HEMA/MMA: 25/75 (VIII), 50/50 (VII), 75/25 (VI), 100/0 (V), where signals with indices $\mathrm{m}$ and $\mathrm{p}$ are related to monomer and polymer, respectively.

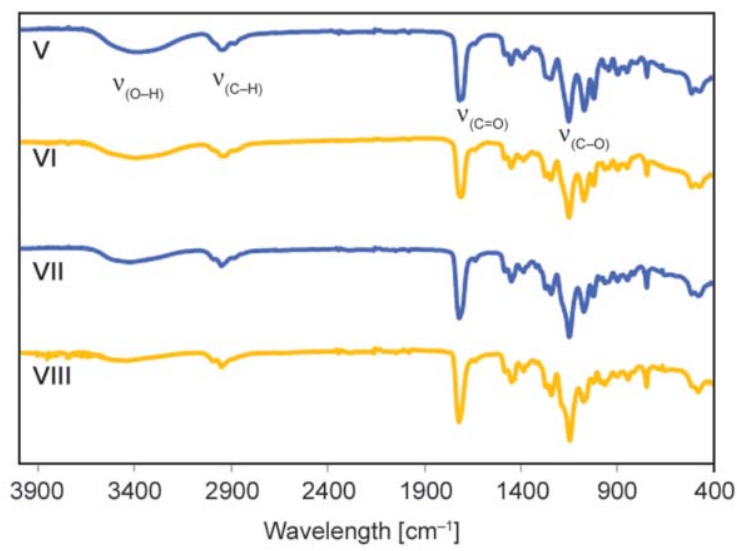

Figure 4. FT-IR spectra for copolymers RETBr/HEMA/ MMA: 100/0 (V), 75/25 (VI), 50/50 (VII), 25/75 (VIII).

$1-10 \%$ of discrepancy as the method errors. Additionally, the monomer conversion measured by GC was used to calculate $M_{\mathrm{n}}$, which in comparison to that determined by GPC disagreed in the case of samples II and VI. These differences were caused by the various natures of solvents in both analyses, that is THF (GPC) vs acetone (GC).

The polymer structures were also confirmed by FT-IR spectra (Figure 4). The presence of the hydroxyl groups is evident by the broad band in region of $3000-3600-\mathrm{cm}^{-1}$ corresponding to $v_{(\mathrm{O}-\mathrm{H})}$ stretching

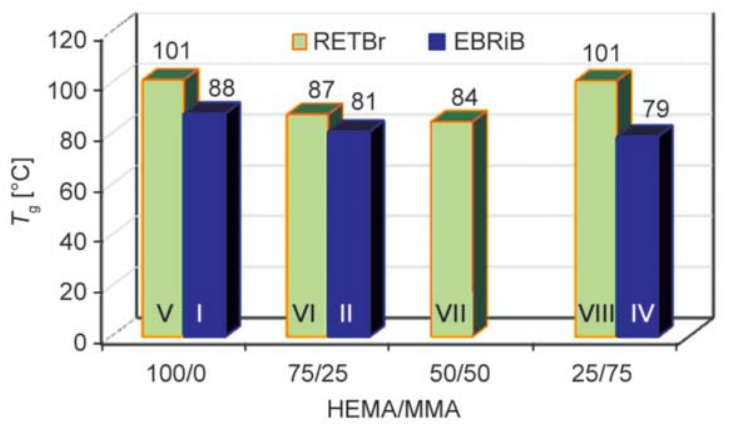

Figure 5. Glass transition temperature for copolymers with various content of HEMA/MMA.

in HEMA units. The peak at $1150 \mathrm{~cm}^{-1}$ corresponds to the stretching vibration of $\mathrm{C}-\mathrm{O}$ and the second peak at $1730 \mathrm{~cm}^{-1}$ to the stretching vibration of $\mathrm{C}=\mathrm{O}$ groups from ester groups.

DSC analysis of the obtained polymers indicated one glass transition temperature $\left(T_{\mathrm{g}}\right)$ in a narrow range of $84-101{ }^{\circ} \mathrm{C}$ (Figure 5). Although comparing both series, $T_{\mathrm{g}}$ 's of the retinol based polymers were slightly higher than for EBriB/HEMA/MMA analogs, whereas in each series the tendency of slight decrease in temperature with reducing number of HEMA units can be observed with exception of copolymer VIII $($ HEMA/MMA $=25 / 75)$ characterized by $T_{\mathrm{g}}$ similar to that of the homopolymer PHEMA. 


\subsection{Micellization and bioactive substance loading}

The self-assembling behaviors of the copolymers were investigated by determination of critical aggregate concentration ( $C M C$, Table 3). $C M C$ values of copolymers were measured by standard procedure using emission spectra of pyrene to form the plot of $I_{336} / I_{332}$ vs the logarithm of the copolymer concentration (Figure 6). It has been noticed that $C M C$ value decreased with the increase in hydrophobic fraction (I, III, IV and VII, VIII) what is the general relationship in the self-assembly process. Similar results have been reported for the studies on other linear amphiphilic copolymers, for example poly $(\varepsilon-$ caprolacton)- $b$-poly(methacrylic acid) [32]. Comparing the samples with equimolar hydrophilic/hydrophobic content (III, VII), aggregates were formed at the same concentrations $(0.014 \mathrm{mg} / \mathrm{ml})$. Similar correlation was observed for samples containing $25 \%$ of hydrophilic fraction (IV and VIII) with significantly lower $C M C(0.0017 \mathrm{mg} / \mathrm{ml})$ than the previous
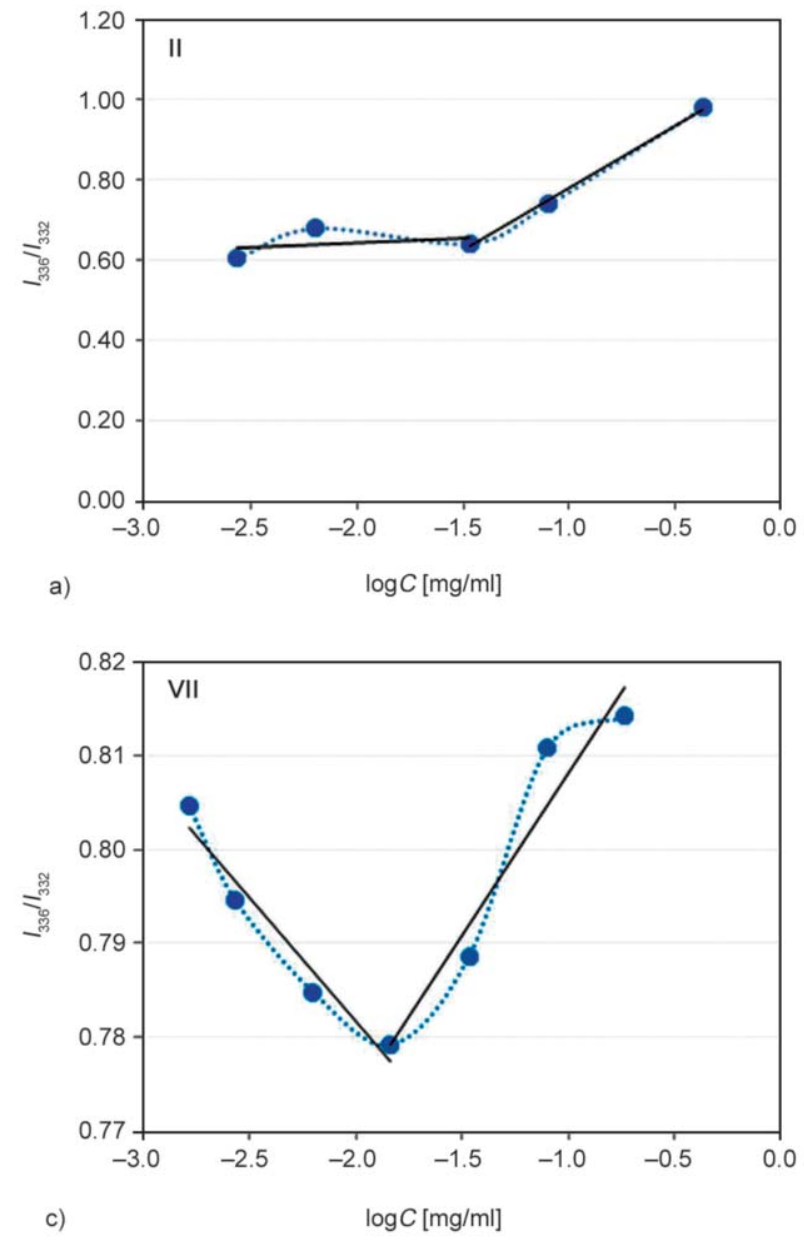

ones, but they provided second $C M C$ point (Figure $6 \mathrm{~b}$, 6d). Double $C M C$ behavior has been described earlier for solution of double hydrophilic block copolymer poly((2-dimethylamino)ethyl methacrylate)- $b$ poly(acrylic acid) with surfactant addition [33] as well as in the case of star-shape statistical copolymers of MMA/methacrylic acid [34].

The hydrodynamic diameters $\left(D_{\mathrm{h}}\right)$ of the particles determined by DLS in water are presented in Table 3. In the series of copolymers obtained with $\mathrm{EBriB}$ (I, III, IV) higher hydrophobic fraction content caused the increase in the particle sizes $(212,566,963 \mathrm{~nm}$, respectively), what is reverse correlation to $C M C$ dependency on the polymer composition. The exception was a copolymer with a predominant hydrophilic fraction (II), which showed a larger $D_{\mathrm{h}}$ than it was expected. In the case of RET-based copolymers with similar chain lengths ( $\mathbf{V}$ and VIII) the yielded self-assemblies reached sizes of $180 \mathrm{~nm}$, whereas almost twice longer chains of polymer VII were aggregated to much bigger particles $(500 \mathrm{~nm})$. After

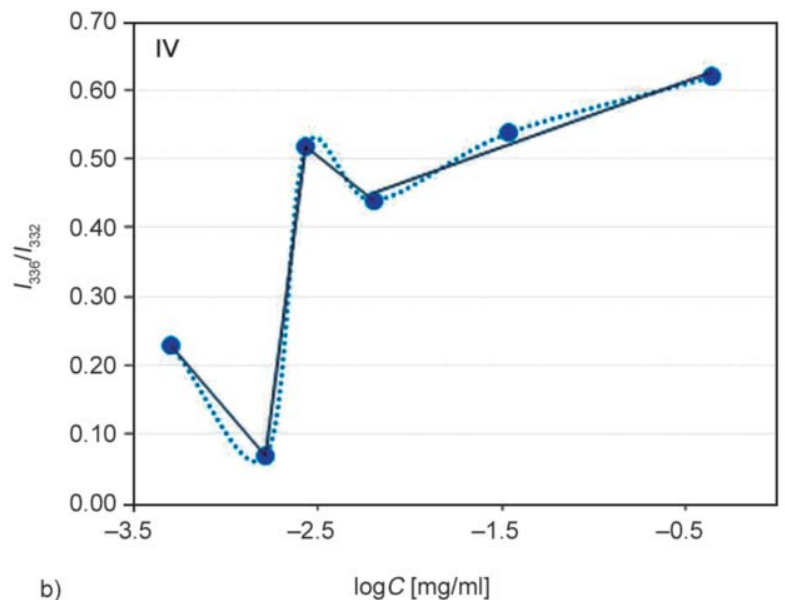

b)

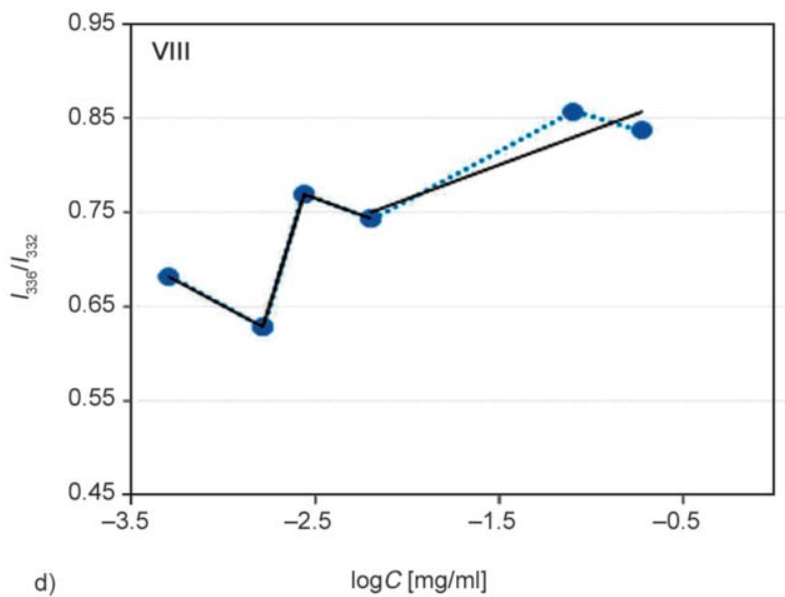

Figure 6. Plots of intensity $I_{336} / I_{332}$ ratio as a function of the logarithm of copolymers concentration in aqueous solution: with single $\mathrm{CMC}(\mathrm{a}, \mathrm{c})$ and double $\mathrm{CMC}(\mathrm{b}, \mathrm{d})$ characteristics. 
drug loading the size of aggregates formed by homopolymer $\mathbf{V}$ or sample VIII increased, while for other samples the particles became smaller. This miscellaneous behavior confirms strong influence of chemical nature of encapsulated substance (FA vs VitC) and starting unit in polymer chain (introduced by various initiators, EBriB vs RETBr), which result different interactions between the bioactive substance and the copolymer varied by hydrophobic/hydrophilic balance. A relationship between $D_{\mathrm{h}}$ and the amount of encapsulated substance was observed for the sample with the smallest $D_{\mathrm{h}}$ after loading $(236 \mathrm{~nm})$ the smallest $D L C$ value $(53 \%)$, whereas in the case of large $D L C$ values ( 87 and $98 \%$ ) a significant increase in the hydrodynamic diameter was observed between the empty and loaded micelles (171 vs. $834 \mathrm{~nm}, 212$ vs. $990 \mathrm{~nm}$ respectively). In some cases of loaded systems (I, III, IV) the measurements showed a few generation of particles with different sizes in the sample, what may indicate the presence of unimers, as well as formation of micelles, aggregates, and even superaggregates (Figure 7).

Generally the polymeric micelles are widely studied as the drug delivery systems, mostly for anti-cancer and anti-inflammatory therapy [34-41]. Satisfactory results have encouraged us to investigate the polymeric micelles also for encapsulation of cosmetic substances that improve the skin functions and appearance. The studies on the self-assembling polymers in the presence of active substance (FA or VitC)

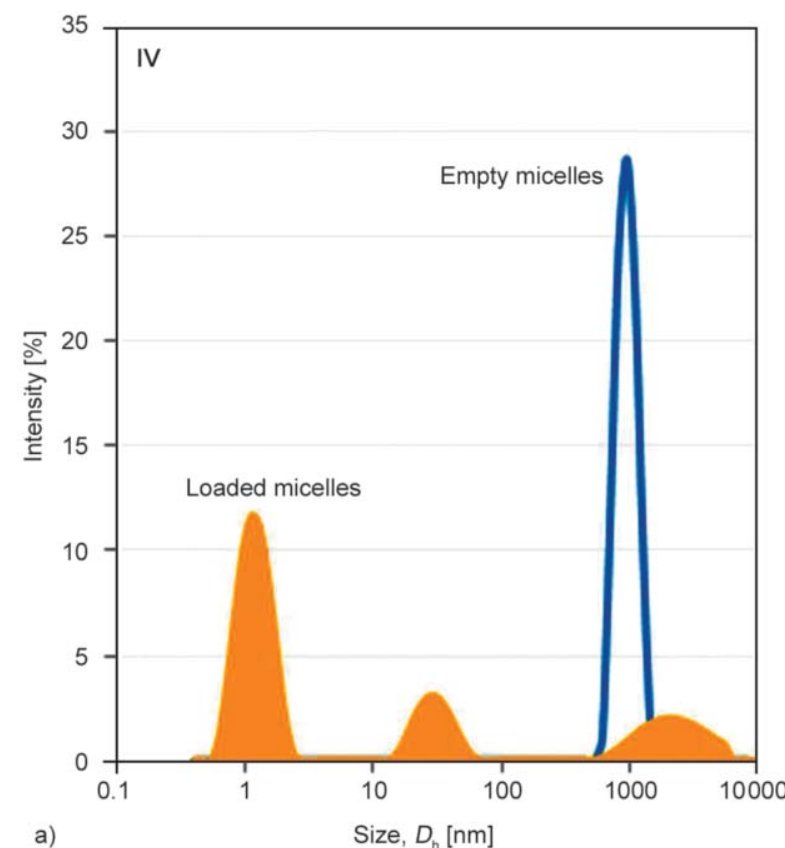

were performed in ratio 1:1. The encapsulation efficiency was verified by drug loading content $(D L C$, Table 3). The copolymers with the high content of the hydrophilic fraction ( $\geq 50 \%$ ) exhibited the optimal polymer-substance interactions with FA yielding almost complete loading (94-98\%), which was in contrary to homopolymer $\mathbf{V}$ encapsulating $53 \%$ of VitC. The copolymers with the predominated hydrophobic fractions (IV, VIII) demonstrated lower $D L C$ (58-66\% of FA and $87 \%$ of VitC), which means this hydrophilic/hydrophobic balance was exceeded to provide the maximal loading efficiency. Although the influence of the loaded substance nature was evident for systems VII and VIII (FA vs VitC) showing opposite tendency of efficiency loading depending on the polymer composition $\left(D L C_{\mathrm{VitC}}<D L C_{\mathrm{FA}}\right.$ at $50 / 50$ and $D L C_{\mathrm{VitC}}>D L C_{\mathrm{FA}}$ at $25 / 75$ of HEMA/ MMA), what confirmed higher polarity of FA and its better interactions with more hydrophilic systems than it was detected for VitC. The presence of RET in the copolymer with $50 \%$ content of the hydrophobic fraction did not affect the FA encapsulation (96\% for III and 94\% for VII), whereas at larger content of the hydrophobic fraction the retinol based system encapsulated slightly less FA than its counterpart obtained with the standard initiator (IV 66\% vs VIII $58 \%$ ). The loading results let us to conclude that the ratio of HEMA/MMA in the copolymer is the crucial factor to design the encapsulated systems with optimized amount of the cosmetic substance.

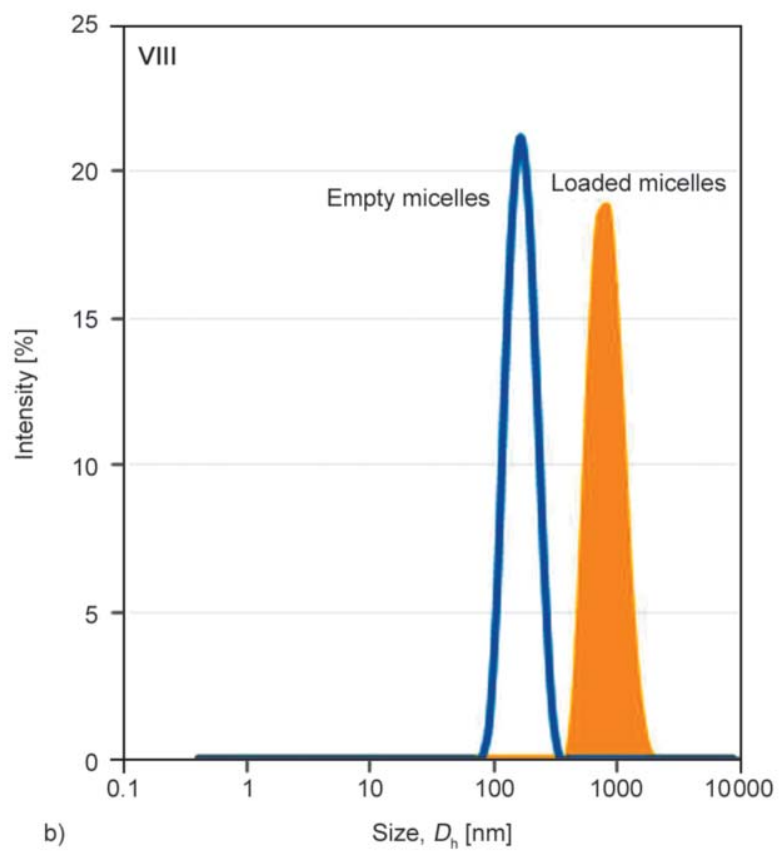

Figure 7. Size distribution plots by intensity for empty and loaded micelles (IV - FA, VIII - VitC) in PBS at $25^{\circ} \mathrm{C}$. 
Table 3. Data of micellization and FA or VitC encapsulation.

\begin{tabular}{|c|c|c|c|c|c|c|}
\hline \multirow[t]{2}{*}{ No. } & \multirow{2}{*}{$\begin{array}{c}M_{1} / M_{2} \\
\text { HEMA/MMA }\end{array}$} & \multirow{2}{*}{$\begin{array}{c}C M C \\
{[\mathrm{mg} / \mathrm{ml}]}\end{array}$} & \multicolumn{2}{|c|}{$\begin{array}{l}\text { Micelle, } D_{\mathrm{h}}{ }^{\mathrm{a}} \\
{[\mathrm{nm}]}\end{array}$} & \multirow{2}{*}{$\begin{array}{c}\text { Encapsulated } \\
\text { substance }\end{array}$} & \multirow{2}{*}{$\begin{array}{l}D L C \\
{[\%]}\end{array}$} \\
\hline & & & empty & loaded & & \\
\hline I & $100 / 0$ & 0.0289 & 212 & $n d f^{b}$ & FA & 97.8 \\
\hline II & $75 / 25$ & 0.0402 & 690 & 407 & FA & 97.8 \\
\hline III & $50 / 50$ & 0.0137 & 566 & $358^{\mathrm{c}}$ & FA & 96.3 \\
\hline IV & $25 / 75$ & $0.0017 / 0.0058$ & 963 & $1.5^{\mathrm{d}}$ & FA & 65.6 \\
\hline $\mathbf{V}$ & $100 / 0$ & nd & 185 & 236 & VitC & 53.1 \\
\hline \multirow{2}{*}{ VII } & \multirow{2}{*}{$50 / 50$} & \multirow{2}{*}{0.0138} & \multirow{2}{*}{500} & 250 & VitC & 78.2 \\
\hline & & & & nd & FA & 94.4 \\
\hline \multirow{2}{*}{ VIII } & \multirow{2}{*}{$25 / 75$} & \multirow{2}{*}{$0.0017 / 0.0057$} & \multirow{2}{*}{171} & 834 & VitC & 86.8 \\
\hline & & & & nd & FA & 57.7 \\
\hline
\end{tabular}

I-IV based on EBriB, V-VIII based on RETBr;

aintensity distribution;

${ }^{b}$ non dominated fraction: $30 \%-12 \mathrm{~nm}, 39 \%-991 \mathrm{~nm}, 26 \%-4618 \mathrm{~nm}$;

c $56 \%, 41 \%-2.0 \mathrm{~nm}, 3 \%-5560 \mathrm{~nm}$;

${ }^{\mathrm{d}} 62 \%, 18 \%-30.5 \mathrm{~nm}, 20 \%-2403 \mathrm{~nm}$;

nd: not determined

\subsection{Bioactive substance release}

The release experiments were carried out in PBS at pH 7.4 for VitC or FA loaded systems, which demonstrated various amounts and release rates of bioactive substance in dependency on the hydrophilic/hydrophobic balance. The largest amounts of bioactive substances were released from micelles based on copolymers containing 50 or $25 \%$ of hydrophilic fraction, that is $93-97 \%$ of FA (III-IV and VIIVIII) without any specific effect of RET units on FA release profile (Figure 8a, 8c, Figure 9). However, the influence of loaded bioactive substance FA vs VitC was detected for copolymers VII-VIII, which were less efficient for release of $\mathrm{VitC}$ evaluated in $48-62 \%$ (Figure $8 b$, Figure 9). In the case of systems with dominantly hydrophilic fractions, including homopolymers, the released amount of FA was slightly lower (71-87\% for I-II), whereas system V (characterized by the smallest $D L C \sim 53 \%$ ), demonstrated the lowest ability to release VitC with the yield of $27 \%$. Comparing the release time for maximum amount, the systems with VitC needed 1 hour, while FA release was extended to 2 hours. Such a short release time is beneficial from the point of view of applying the tested systems in cosmetic products used in the form of masks, wraps or creams, which time of application on the skin is usually short because the active substance penetrates into the skin to stimulate dedicated processes.

In our studies the term of maximum amount of release substance into the solution means that further its release corresponded to lower concentration
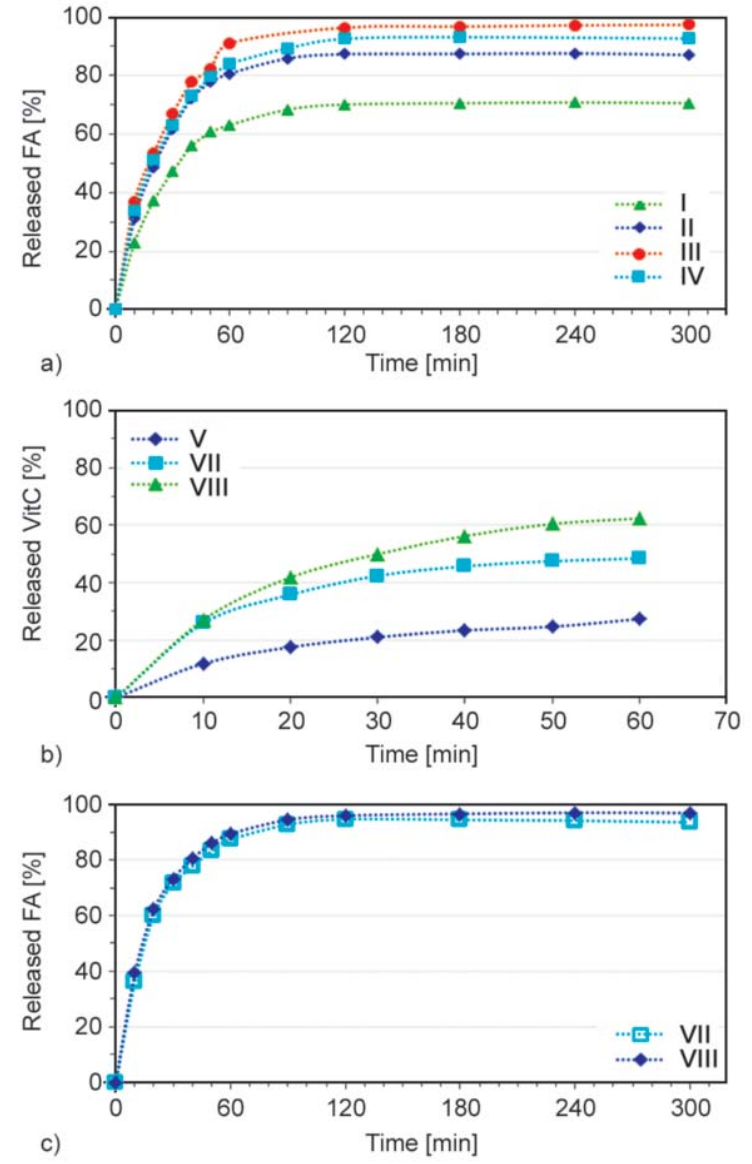

Figure 8. Release profiles for micelles loaded with FA (a, c) and VitC (b).

instead of being on constant level. This phenomenon may be explained by the degradation of the active substance as a response to sun or artificial light exposure (the samples were not protected from daylight during release) as well as its tendency to particle aggregation. 


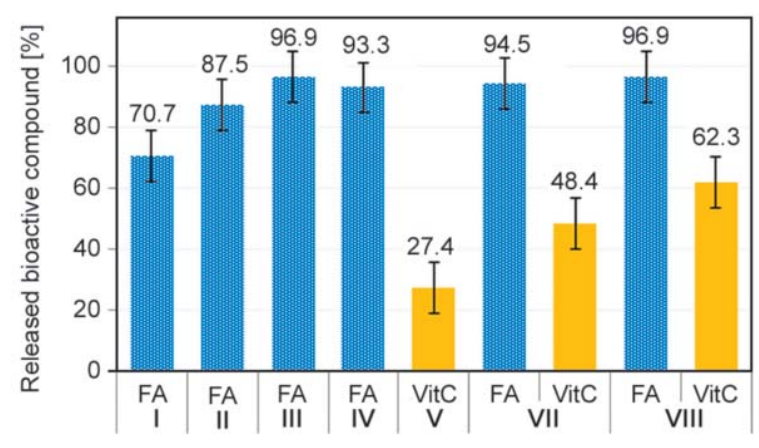

Figure 9. Maximum amount of bioactive compound released after $3 \mathrm{~h}$ for FA and $1 \mathrm{~h}$ for VitC.

The influence of light on the release was confirmed by additional experiment with inclusion of a strong lightening source during the process, what resulted in a sudden decrease in the concentration of FA in the test sample compared to the sample exposed to the daylight (Figure 10a). Aggregation was observed by $D L S$ analysis of the buffer solution taken after reaching the maximum release point in the process. This test showed formation of a much larger particles (corresponding to aggregates) than the micelles before the release process, e.g. 236 vs. $852 \mathrm{~nm}$ for the system $\mathbf{V}$ (Figure 10b).

\section{Conclusions}

Bromoester modified retinol was used as novel bioinitiator in the $\mathrm{Cu}$-mediated ATRP to prepare copolymers of HEMA/MMA with various hydrophilic/hydrophobic balance supporting the selfassembly behavior in aqueous solution at room temperature. The copolymers with a predominantly

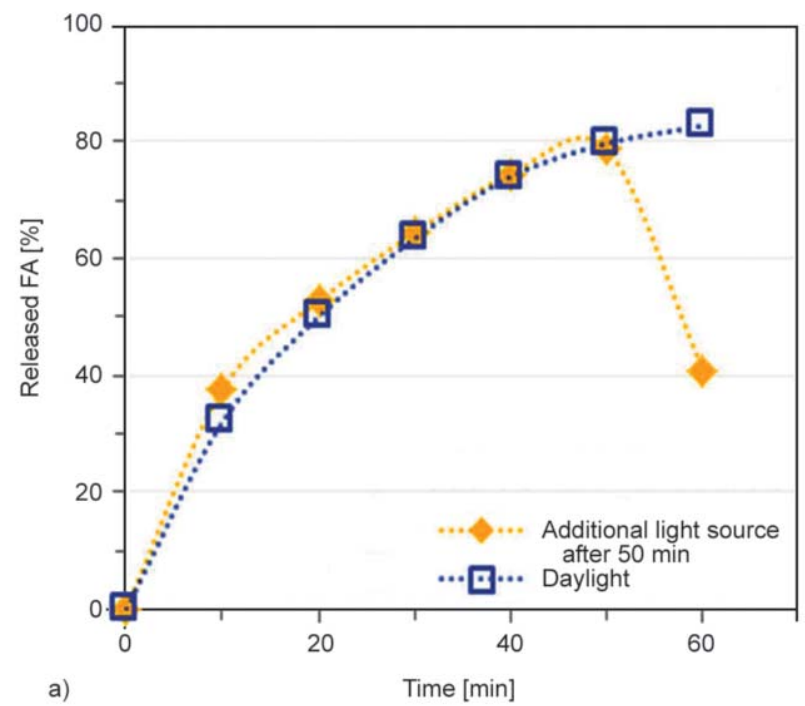

hydrophilic fraction showed better ability to form micelles, what was indicated by higher $C M C$ values, in contrary to that with predominantly hydrophobic fraction. Most of the systems demonstrated satisfactory efficiencies of cosmetic substance encapsulation (78-98\% of FA or VitC), but the ratio of HEMA/ MMA in the copolymer was found to be a crucial factor regulating the encapsulation processes. The systems were proficient to release the maximum of active substance within 1 or $2 \mathrm{~h}$ depending on the encapsulated substance (VitC vs FA, respectively). In respect to both encapsulation and release studies, the polymers with 50/50 of HEMA/MMA for FA loading, including RET based ones, and 25/75 for VitC, provided the best micellar systems, which need to be tested for toxicity and diffusion through the artificial skin to verify their application in cosmetology. The biological and non-toxic nature of retinol starting unit can be additionally beneficial for improvement of the skin treatment. Because of that the retinol based amphiphilic copolymers with adjustable characteristics are postulated as excellent carriers of active substances, including the option of their convenient distribution into the skin by in via masks, under-eye patches, and wraps.

\section{Acknowledgements}

Scientific work financed from budget funds for science in the years 2017-2020 as a research project under the 'Diamond Grant' program supported by Ministry of Science and Higher Education (MNiSW, Poland), ID number: DI2016 008246. The authors thank Dr Anna Mielańczyk for GPC analysis (Silesian University of Technology).

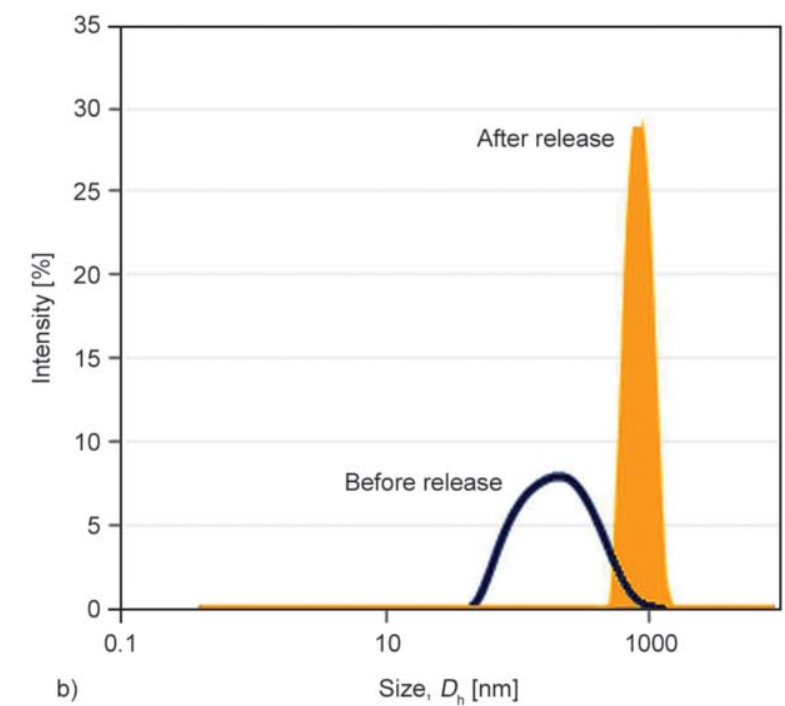

Figure 10. The influence of light on FA release on the example of copolymer II (a) and aggregation of released VitC from polymer system $\mathbf{V}$ (b) as the side effects. 


\section{References}

[1] Gianeti M. D., Wagemaker T. A. L., Seixas V. C., Maia Campos P. M. B. G.: The use of nanotechnology in cosmetic formulations: The influence of vehicle in the vitamin A skin penetration. Current Nanoscience, 8, 526534 (2012).

https:://doi.org/10.2174/157341312801784375

[2] Wójcik A., Bartnicka E., Rotsztejn H.: Reviscometer evaluation of the skin condition after applying retinol and vitamin $\mathrm{C}$ complex in menopausal women. Journal of Cosmetics, Dermatological Sciences and Applications, 6, 148-155 (2016).

https:://doi.org/10.4236/jcdsa.2016.64019

[3] Zhao J., Schlaad H., Weidner S., Antonietti M.: Synthesis of terpene-poly(ethylene oxide)s by t-BuP4-promoted anionic ring-opening polymerization. Polymer Chemistry, 3, 1763-1768 (2012).

https:://doi.org/10.1039/c1py00388g

[4] Yildirim I., Yildirim T., Kalden D., Festag G., Fritz N., Weber C., Schubert S., Westerhausen M., Schubert U. S.: Retinol initiated poly(lactide)s: Stability upon polymerization and nanoparticle preparation. Polymer Chemistry, 8, 4378-4387 (2017).

https:://doi.org/10.1039/C7PY00881C

[5] Syed B., Baig M. D., Dada Khalandar K. S., Varma R. K.: Design and evaluation of novel retinol-encapsulated chitozan nanoparticles. Journal of Drug Delivery Research, 2, 24-36 (2013).

[6] Park C-E., Park D-J., Kim B-K.: Effects of a chitosan coating on properties of retinol- encapsulated zein nanoparticles. Food Science and Biotechnology, 24, 17251733 (2015).

https:://doi.org/10.1007/s10068-015-0224-7

[7] Huang S-J., Sun S-L., Chiu C-C., Wang L-F.: Retinolencapsulated water-soluble succinated chitosan nanoparticles for antioxidant applications. Journal of Biomaterial Science, 24, 315-329 (2013).

https:://doi.org/10.1080/09205063.2012.690278

[8] Cho E-C.: Effect of polymer characteristics on the thermal stability of retinol encapsulated in aliphatic polyester nanoparticles. Bulletin of the Korean Chemical Society, 33, 2560-2566 (2012).

https:://doi.org/10.5012/bkcs.2012.33.8.2560

[9] Hwang Y-J., Oh C., Oh S-G.: Controlled release of retinol from silica particles prepared in $\mathrm{O} / \mathrm{W} / \mathrm{O}$ emulsion: the effects of surfactants and polymers. Journal of Controlled Release, 106, 339-349 (2005).

https:://doi.org/10.1016/j.jconrel.2005.05.007

[10] Lee M-H., Oh S-G., Moon S-K., Bae S-Y.: Preparation of silica particles encapsulating retinol using $\mathrm{O} / \mathrm{W} / \mathrm{O}$ multiple emulsions. Journal of Colloid and Interface Science, 240, 83-89 (2001).

https:://doi.org/10.1006/jcis.2001.7699
[11] Müller W. E. G., Tolba E., Schröder H. C., Diehl-Seifert B., Wang X.: Retinol encapsulated into amorphous $\mathrm{Ca}^{2+}$ polyphosphate nanospheres acts synergistically in MC3T3-E1 cells. European Journal of Pharmaceutics and Biopharmaceutics, 93, 214-223 (2015).

https:://doi.org/10.1016/j.ejpb.2015.04.005

[12] Jenning V., Schäfer-Korting M., Gohla S.: Vitamin A-loaded solid lipid nanoparticles for topical use: Drug release properties. Journal of Controlled Release, 66, 115-126 (2000).

https:://doi.org/10.1016/S0168-3659(99)00223-0

[13] Jenning V., Gohla S. H.: Encapsulation of retinoids in solid lipid nanoparticles (SLN). Journal of Microencapsulation, 18, 149-158 (2001).

https:://doi.org/10.1080/02652040010000361

[14] Al-Niaimi F., Chiang N. Y. Z.: Topical vitamin C and the skin: Mechanisms of action and clinical applications. Journal of Clinical and Aesthetic Dermatology, 10, 14-17 (2017).

[15] Keller K. L., Fenske N. A.: Uses of vitamins A, C, and E and related compounds in dermatology: A review. Journal of the American Academy of Dermatology, 39, 611625 (1998). https:://doi.org/10.1016/S0190-9622(98)70011-8

[16] Ou S., Kwok K-C.: Ferulic acid: Pharmaceutical functions, preparation and applications in foods. Journal of the Science of Food and Agriculture, 84, 1261-1269 (2004). https:://doi.org/10.1002/jsfa.1873

[17] Kumar N., Pruthi V.: Potential applications of ferulic acid from natural sources. Biotechnology Reports, 4, 8693 (2014).

https:://doi.org/10.1016/j.btre.2014.09.002

[18] Taofiq O., Gonzalez-Paramás A. M., Barreiro M. F., Ferreira I.: Hydroxycinnamic acids and their derivatives: Cosmeceutical significance, challenges and future perspectives, A review. Molecules, 22, 281-304 (2017). https:://doi.org/10.3390/molecules22020281

[19] Poornima B., Korrapati P. S.: Fabrication of chitosanpolycaprolactone composite nanofibrous scaffold for simultaneous delivery of ferulic acid and resveratrol. Carbohydrate Polymers, 157, 1741-1749 (2017). https:://doi.org/10.1016/j.carbpol.2016.11.056

[20] Centini M., Maggiore M., Casolaro M., Andreassi M., Facino R. M., Anselmi C.: Cyclodextrins as cosmetic delivery systems. Journal of Inclusion Phenomena and Macrocyclic Chemistry, 57, 109-112 (2007). https:://doi.org/10.1007/s10847-006-9212-0

[21] Kim J. S., Youk J. H.: Preparation of core cross-linked micelles using a photo-cross-linking agent. Polymer, 50, 2204-2208 (2009). https:://doi.org/10.1016/j.polymer.2009.03.013 
[22] Neugebauer D.: Modifications of hydroxyl-functionalized HEA/HEMA and their polymers in the synthesis of functional and graft copolymers. Current Organic Synthesis, 14, 798-809 (2017). https:://doi.org/10.2174/1570179414666161115163449

[23] Popescu D., Keul H., Möller M.: Functional and reactive polymethacrylates suitable for preparation of peptide/protein-polymer conjugates. Reactive and Functional Polymers, 70, 767-774 (2010).

https:://doi.org/10.1016/j.reactfunctpolym.2010.07.016

[24] Szanka A., Szarka G., Iván B.: Poly(methyl methacrylate-co-2-hydroxyethyl methacrylate) four-arm star functional copolymers by quasiliving ATRP: Equivalent synthetic routes by protected and nonprotected HEMA comonomers. Journal of Macromolecular Science Part A: Pure and Applied Chemistry, 51, 125-133 (2014). https:://doi.org/10.1080/10601325.2014.864921

[25] Fan X., Wang G., Zhang Z., Huang J.: Synthesis and characterization of amphiphilic heterograft copolymers with PAA and PS side chains ia 'grafting from' approach. Journal of Polymer Science Part A: Polymer Chemistry, 49, 4146-4153 (2011).

https:://doi.org/10.1002/pola.24856

[26] Börner H. G., Duran D., Matyjaszewski K., da Silva M., Sheiko S. S.: Synthesis of molecular brushes with gradient in grafting density by atom transfer polymerization. Macromolecules, 35, 3387-3394 (2002).

https:://doi.org/10.1021/ma012100a

[27] Ydens I., Degée P., Dubois P., Libiszowski J., Duda A., Penczek S.: Combining ATRP of methacrylates and ROP of L,L-dilactide and $\varepsilon$-caprolactone. Macromolecular Chemistry and Physics, 204, 171-179 (2003). https:://doi.org/10.1002/macp.200290071

[28] Durmaz Y. Y., Kumbaraci V., Demirel A. L., Talinli N., Yagci Y.: Graft copolymers by the combination of ATRP and photochemical acylation process by using benzodioxinones. Macromolecules, 42, 3743-3749 (2009). https:://doi.org/10.1021/ma900360s

[29] Erol F. E., Sinirlioglu D., Cosgun S., Muftuoglu A. E.: Synthesis of fluorinated amphiphilic block copolymers based on PEGMA, HEMA, and MMA via ATRP and CuAAC click chemistry. International Journal of Polymer Science, 2014, 1-11 (2014).

https:://doi.org/10.1155/2014/464806

[30] Xiong L., Liang H., Wang R., Chen L.: A novel route for the synthesis of poly(2-hydroxyethyl methacrylateco-methyl methacrylate) grafted titania nanoparticles via ATRP. Journal of Polymer Research, 18, 1017-1021 (2011). https:://doi.org/10.1007/s10965-010-9502-5

[31] Ghamkhari A., Agbolaghi S., Poorgholy N., Massoumi B.: pH-responsive magnetic nanocomposites based on poly(2-succinyloxyethyl methacrylate-co-methylmethacrylate) for anticancer doxorubicin delivery applications. Journal of Polymer Research, 25, 1-37 (2018). https:://doi.org/10.1007/s10965-017-1431-0
[32] Hu J., He J., Zhang M., Ni P.: Precise modular synthesis and a structure-property study of acid-cleavable starblock copolymers for PH-triggered drug delivery. Polymer Chemistry, 6, 1553-1566 (2014).

https:://doi.org/10.1039/c4py01391c

[33] Han X., Xiong Z., Zhang X., Liu H.: Multi-tunable selfassembled morphologies of stimuli-responsive diblock polyampholyte films on solid substrates. Soft Matter, 11, 2139-2146 (2015). https:://doi.org/10.1039/C5SM00025D

[34] Mielańczyk A., Odrobińska J., Grządka S., Mielańczyk Ł., Neugebauer D.: Miktoarm star copolymers from D-(-)-salicin core aggregated into dandelion-like structures as anticancer drug delivery systems: Synthesis, self-assembly and drug release. International Journal of Pharmaceutics, 515, 515-526 (2016).

https:://doi.org/10.1016/j.ijpharm.2016.10.034

[35] Neugebauer D., Odrobińska J., Bielas R., Mielańczyk A.: Design of systems based on 4-armed star-shaped polyacids for indomethacin delivery. New Journal of Chemistry, 40, 10002-10011 (2016).

https:://doi.org/10.1039/C6NJ02346K

[36] Bury K., Neugebauer D.: Novel self-assembly graft copolymers as carriers for anti-inflammatory drug delivery. International Journal of Pharmaceutics, 460, 150 157 (2014).

https:://doi.org/10.1016/j.ijpharm.2013.10.051

[37] Bury K., Du Prez F., Neugebauer D.: Self-assembling linear and star shaped poly( $\varepsilon$-caprolactone)/poly[(meth) acrylic acid] Block copolymers as carriers of indomethacin and quercetin. Macromolecular Bioscience, 13, 1520-1530 (2013). https:://doi.org/10.1002/mabi.201300179

[38] Maksym-Bębenek P., Neugebauer D.: Study on self-assembled well-defined PEG graft copolymers as efficient drug-loaded nanoparticles for anti-inflammatory therapy. Macromolecular Bioscience, 15, 1616-1624 (2015).

https:://doi.org/10.1002/mabi.201500189

[39] Maksym P., Neugebauer D.: Synthesis of amphiphilic semigrafted pseudo-pluronics for self-assemblies carrying indomethacin. RSC Advances, 6, 88444-88452 (2016). https:://doi.org/10.1039/C6RA20368J

[40] Maksym-Bębenek P., Neugebauer D.: Self-assembling polyether-b-polymethacrylate graft copolymers loaded with indomethacin. International Journal of Polymeric Materials and Polymeric Biomaterials, 66, 317-325 (2017).

https:://doi.org/10.1080/00914037.2016.1201832

[41] Bielas R., Łukowiec D., Neugebauer D.: Drug delivery via anion exchange of salicylate decorating poly(meth) acrylates based on a pharmaceutical ionic liquid. New Journal of Chemistry, 41, 12801-12807 (2017). https:://doi.org/10.1039/C7NJ02667F 